\title{
Comprehensive Two-Dimensional Gas Chromatography with Time of Flight Mass Spectrometry Applied to Analysis of Fischer-Tropsch Synthesis Products Obtained with and without Carbon Dioxide Addition to Feed Gas
}

\author{
Raphael S. F. Silva, ${ }^{* a}$ Juliana B. Tamanqueira, ${ }^{b}$ Julio César M. Dias, ${ }^{b}$ Fábio M. Passarelli, ${ }^{b}$ \\ Antonio Marcos F. Bidart, ${ }^{b}$ Francisco R. Aquino Neto ${ }^{a}$ and Débora A. Azevedo ${ }^{*, a}$ \\ anstituto de Química, LAGOA-LADETEC, Universidade Federal do Rio de Janeiro, \\ Cidade Universitária, Ilha do Fundão, 21941-909 Rio de Janeiro-RJ, Brazil \\ ${ }^{b}$ Petrobras/Cenpes/PDP/TPAP, Cidade Universitária, Ilha do Fundão, \\ 21941-915 Rio de Janeiro-RJ, Brazil
}

\begin{abstract}
A cromatografia gasosa bidimensional abrangente acoplada à espectrometria de massas por tempo de vôo (CG×CG-EMTDV) foi aplicada para avaliar o efeito do $\mathrm{CO}_{2}$ sobre a distribuição dos $n$-alcanos, alcanos ramificados, alquenos e compostos oxigenados em produtos da reação de Fischer-Tropsch. Coeluições de material não resolvido observadas em CG convencional foram resolvidas por CG×CG-EMTDV.
\end{abstract}

Comprehensive two-dimensional gas chromatography coupled to time of flight mass spectrometry ( $\mathrm{GC} \times \mathrm{GC}$-TOFMS) was applied to evaluate the $\mathrm{CO}_{2}$ effect on distribution of $n$-alkanes, branched alkanes, alkenes and oxygen-containing compounds in Fischer-Tropsch products. GC $\times$ GC-TOFMS was able to resolve the unresolved compounds observed in conventional GC.

Keywords: GC $\times$ GC, Fischer-Tropsch products, comprehensive two-dimensional GC

\section{Introduction}

Worldwide demand for clean, reliable and environmental friendly energy sources has never been greater. Based on that scenario, Gas to Liquids (GTL) solutions, a group of technologies that can create liquid hydrocarbon fuels from natural gas, has become more and more attractive as a way to commercialize stranded gas reserves. In this context, stranded reserves mean any natural gas field which the infrastructure of transportation to the market is not feasible for technical or economic reasons. Also, GTL could be a possible solution to limit natural gas flaring or venting. An important part of GTL is the Fischer-Tropsch (FT) synthesis, which is a catalytic reaction wherein a mixture of carbon monoxide $(\mathrm{CO})$ and hydrogen $\left(\mathrm{H}_{2}\right)$ called syngas (from methane reforming process) are converted into hydrocarbons of wide range of molecular weights often called synthetic crude (syncrude). The Fischer Tropsch synthesis is so far one of the best ways to convert natural gas into liquid fuels. ${ }^{1-3}$

*e-mail: raphaelslls@yahoo.com.br, debora@iq.ufrj.br
Conversion of syngas through the FT process leads to a distribution of products essentially consisting of $n$-alkanes together with smaller percentages of branched alkanes, alcohols, alkenes. The main reactions involved in FT synthesis are shown in Figure 1.

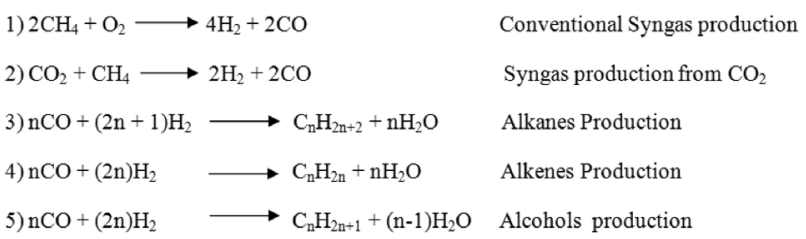

Figure 1. Main chemical reactions in Fischer-Tropsch synthesis.

The FT reactions occur under catalytic conditions, $\mathrm{Fe}$ and $\mathrm{Co}$ are the most used catalysts, although $\mathrm{Ru}, \mathrm{Ni}$ and other transition metals have also been tested. ${ }^{4}$ Although the FT has been known since the early 20th century, its reaction mechanism is not completely elucidated yet. Two main proposals are dominant: the oxygenated mechanism ${ }^{5,6}$ and the surface carbide mechanism. ${ }^{7,8}$ Investigations about the FT mechanism are made even nowadays. Recently published evidences suggest that FT reaction, under iron 
catalyst, occurs by the surface carbide mechanism, ${ }^{9}$ while the oxygenated mechanism prevails when the reaction occurs under cobalt catalyst. ${ }^{10}$

The FT heavy products from the low temperature FT process can be upgraded to obtain high quality products such as diesel, jet fuel, petrochemical naphtha, lubricants and food grade waxes. Such cuts are considered sulfur and nitrogen free and the level of aromatic compounds is extremely low (less than $1 \mathrm{ppm}$ ). Then, GTL from FT process provides cleaner fuels (less emission and pollution). ${ }^{11-13}$

Besides the mentioned benefits, GTL technology could also be used as a means to mitigate $\mathrm{CO}_{2}$ emission via carbon capture through $\mathrm{CO}_{2}$ chemical conversion into liquid fuels. ${ }^{14,15}$ The $\mathrm{CO}_{2}$ source can be obtained from the plant emission (combustion process, side reforming reaction and FT reaction), from external sources like $\mathrm{CO}_{2}$ rich natural gas, different types of anthropogenic processes, and even from the ocean. ${ }^{16}$

Normally the products formed are dispersed in liquid and solid phases. In addition, many isomers are produced, which makes FT products complex samples. The analysis of FT samples is crucial for process monitoring and ensures that the wanted products are obtained. However, the complexity of the FT samples requires analytical techniques with high separation power and comprehensive two-dimensional gas chromatography $(\mathrm{GC} \times \mathrm{GC})$ is a good option to analyze them.

GC $\times$ GC was earlier described by Lui and Philips, ${ }^{17}$ the two-dimensional system consisting in two columns with different stationary phases which are connected in tandem and all compounds that elute from the first column are injected in the second one. In $\mathrm{GC} \times \mathrm{GC}$ the compounds are submitted to two separation mechanisms which distributes the compounds in an orthogonal plane, increasing the information about the samples. Details are available in the literature review articles which explain the theoretical and practical aspects about the technique. ${ }^{18-20}$

$\mathrm{GC} \times \mathrm{GC}$ can be coupled to several kinds of detectors, ${ }^{21}$ but the most powerful combination is $\mathrm{GC} \times \mathrm{GC}$ coupled to time of flight mass spectrometry (GC $\times$ GC-TOFMS) because of its high acquisition rate (up to 500 spectra s ${ }^{-1}$. ${ }^{22}$

In this work, $\mathrm{GC} \times \mathrm{GC}-\mathrm{TOFMS}$ was used to the analysis of Fisher-Tropsch-oil products to evaluate the $\mathrm{CO}_{2}$ effect on product composition.

\section{Experimental}

\section{Sample description}

The FT products were obtained using $\mathrm{Co} / \mathrm{Al}_{2} \mathrm{O}_{3}$ catalyst in a fixed bed reactor operating at $\mathrm{T}=220^{\circ} \mathrm{C}, \mathrm{P}=25 \mathrm{bar}$ and
$\mathrm{H}_{2} / \mathrm{CO}$ ratio of 1.9. Two Fischer-Tropsch streams, named as FT1 and FT2, were generated and analyzed in this study; FT1 was obtained from synthetic syngas $\left(\mathrm{CO}+\mathrm{H}_{2}\right.$ mixture from gas bottles) while to produce FT2, the synthetic syngas was blended with $10 \%$ of $\mathrm{CO}_{2}$. The samples were fractionated in liquid and solid phases employing separators operating under controlled temperature and pressure. The solid fraction is obtained under high pressure and high temperature and liquid fraction is obtained under high pressure and low temperature, both fractions are obtained free of water. The samples were named as follows: FT1 liquid phase (FT1-L), FT2 liquid phase (FT2-L), FT1 solid phase (FT1-S) and FT1 solid phase (FT2-S). Liquid samples were injected directly, while the solid samples

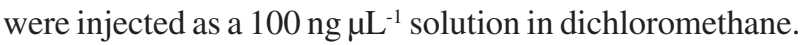

\section{D-HTGC analysis}

Analyses by high temperature gas chromatography (1D-HTGC) were performed in a AC Agilent 6890N Network GC System (Palo Alto, CA, EUA) employing a PTV inlet (programmed temperature vaporization) and a FID detector (flame ionization detector). The column used was a HT-750 column (Analytical Controls, Houston, TX, EUA), $100 \%$ methylsiloxane, $5 \mathrm{~m} \times 0.53 \mathrm{~mm}$ i.d. $\times$ $0.09 \mu \mathrm{m} \mathrm{d}_{\mathrm{f}}$.

Chromatographic conditions for liquid and solid samples, $1 \mu \mathrm{L}$ was injected in a PTV inlet programmed at $-20^{\circ} \mathrm{C}$ initial temperature ramped at $10^{\circ} \mathrm{C} \mathrm{min}^{-1}$ to $430{ }^{\circ} \mathrm{C}$ (5 min). The oven temperature program was $80^{\circ} \mathrm{C}$ initial temperature, ramped $15^{\circ} \mathrm{C} \mathrm{min}^{-1}$ to $430^{\circ} \mathrm{C}$ (26 min). Helium was used as carrier gas at constant flow $22.5 \mathrm{~mL} \mathrm{~min}^{-1}$. Detector temperature was set at $430{ }^{\circ} \mathrm{C}$, air: $350 \mathrm{~mL} \mathrm{~min}^{-1}$, hydrogen: $35 \mathrm{~mL} \mathrm{~min}{ }^{-1}$, helium $4 \mathrm{~mL} \mathrm{~min}^{-1}$.

\section{GC $\times$ GC-TOFMS analysis}

Analyses by GC $\times$ GC-TOFMS were performed on a Pegasus 4D system (Leco, St. Joseph, MI, USA), composed by an Agilent 6890 GC (Palo Alto, CA, USA) equipped with a secondary oven and a non-moving quadjet dual-stage modulator and a Pegasus III (Leco, St. Joseph, MI, USA) time-of-flight mass spectrometer. A DB-5 column (Agilent, Palo Alto, CA, USA), 5\%-phenyl95\%-methylsiloxane $\left(30 \mathrm{~m} \times 0.25 \mathrm{~mm}\right.$ i.d., $\left.0.25 \mathrm{~mm} \mathrm{~d}_{\mathrm{f}}\right)$ was used as the first dimension column ( $\left.{ }^{1} \mathrm{D}\right)$. A BPX-50 column (SGE, Ringwood, VIC, Australia), 50\%-phenyl$50 \%$-methylsiloxane $\left(1.5 \mathrm{~m} \times 0.1 \mathrm{~mm}\right.$ i.d., $\left.0.1 \mu \mathrm{m} \mathrm{d}_{\mathrm{f}}\right)$ was used as the second dimension column $\left({ }^{2} \mathrm{D}\right)$. The ${ }^{2} \mathrm{D}$ column was transferred to the TOFMS by means of a $0.5 \mathrm{~m} \times 0.25 \mathrm{~mm}$ i.d. empty deactivated fused silica capillary, 
which was connected via SGE mini-unions and Siltite ${ }^{\mathrm{TM}}$ metal ferrules 0.1-0.25 mm i.d. (Ringwood, VIC, Australia).

GC conditions for liquid samples: 300:1 split mode injection of $1 \mu \mathrm{L}$ at $250^{\circ} \mathrm{C}$. Helium was used as carrier gas at a constant flow rate of $1.0 \mathrm{~mL} \mathrm{~min}^{-1}$. The primary oven temperature program was set at $32{ }^{\circ} \mathrm{C}$ for $5 \mathrm{~min}$, ramped at $3{ }^{\circ} \mathrm{C} \mathrm{min}-1$ to $220{ }^{\circ} \mathrm{C}$. The secondary oven temperature program was $10^{\circ} \mathrm{C}$ higher than the primary. The modulation period was $3 \mathrm{~s}$ with $0.75 \mathrm{~s}$ hot pulse duration and the modulator temperature was $30^{\circ} \mathrm{C}$ higher than the primary oven temperature.

GC conditions for solid samples: 50:1 split mode injection of $1 \mu \mathrm{L}$ at $250{ }^{\circ} \mathrm{C}$. Helium was used as carrier gas at a constant flow rate of $1.0 \mathrm{~mL} \mathrm{~min}{ }^{-1}$. The primary oven temperature program was: $70{ }^{\circ} \mathrm{C}$ for $1 \mathrm{~min}$, ramped at $3{ }^{\circ} \mathrm{C} \mathrm{min}^{-1}$ to $300{ }^{\circ} \mathrm{C}$. The secondary oven temperature program was $10^{\circ} \mathrm{C}$ higher than the primary. The modulation period was $3 \mathrm{~s}$ with $0.75 \mathrm{~s}$ hot pulse duration and the modulator temperature was $30^{\circ} \mathrm{C}$ higher than the primary oven temperature.

For all analyses the transfer line to the MS was at $280^{\circ} \mathrm{C}$, the electron ionization at $70 \mathrm{eV}$, the mass range of $\mathrm{m} / \mathrm{z} 35-600$, the ion source temperature was $200{ }^{\circ} \mathrm{C}$, the detector was at $-1700 \mathrm{~V}$ and the acquisition rate was 100 spectra s ${ }^{-1}$.

\section{Data processing for $G C \times G C$-TOFMS}

GC $\times$ GC-TOFMS data acquisition and processing were performed with ChromaTOF software version 4.0 (Leco, St. Joseph, MI, USA). Individual peaks were automatically detected on the basis of a 10:1 signal to noise ratio. Areas of the individual peaks were automatically acquired.

\section{Results and Discussion}

Comprehensive two-dimensional gas chromatography coupled to time of flight mass spectrometry $(\mathrm{GC} \times$ GC-TOFMS) was employed to analyze unresolved material observed in ${ }^{1} \mathrm{D}$-HTGC and evaluate the $\mathrm{CO}_{2}$ effect on the distribution of $n$-alkanes, branched alkanes, alkenes and oxygen-containing compounds in the samples.

The selected column set had non-polar versus polar configuration, where separation in ${ }^{1} \mathrm{D}$ was based on the volatility while in ${ }^{2} \mathrm{D}$ the separation was based on the polarity of the compounds. The configuration non-polar versus polar columns is the most often applied to petrochemical samples. ${ }^{23-25}$ However, some works have been published reporting $\mathrm{GC} \times \mathrm{GC}$ analyses for petrochemical samples with polar versus non-polar configuration. ${ }^{26,27}$

$\mathrm{GC} \times \mathrm{GC}$ has been used for the analysis of FT products with configuration non-polar versus polar, ${ }^{28}$ as well as polar versus non-polar configuration with $\mathrm{GC} \times \mathrm{GC}-\mathrm{TOFMS}^{29}$ and GC $\times$ GC-FID. ${ }^{30}$

${ }^{1} \mathrm{D}$-HTGC analyses detected $n$-alkanes ranging from $\mathrm{C}_{4}$ to $\mathrm{C}_{15}$ for the liquid samples (FT1-L and FT2-L) and $n$-alkanes ranging from $\mathrm{C}_{6}$ to more than $\mathrm{C}_{50}$ for the solid ones (FT1-S and FT2-S). A typical ${ }^{1} \mathrm{D}-\mathrm{CTGC}$ chromatogram of the FT-2S sample is presented in Figure 2, where unresolved compounds can be observed at the range $\mathrm{C}_{9}$ to $\mathrm{C}_{30}$.

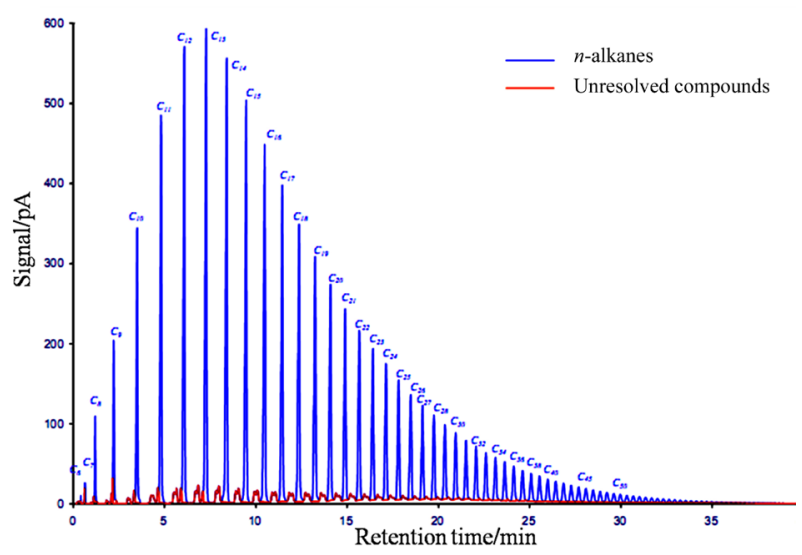

Figure 2. One-dimensional chromatogram for FT2-S sample showing unresolved material which was resolved by GC $\times$ GC-TOFMS.

The detection of alcohols in FT samples is difficult because these compounds coelute in non-polar columns with branched alkanes, when analyzed by 1D-GC. This problem was solved by GC $\times$ GC-TOFMS. Figure 3 shows a twodimensional chromatogram for the FT1-L sample where two chromatographic bands can be seen, the lower band is formed by hydrocarbons and the upper one by $n$-alcohols which are more retained by the medium polar column (BPX-50) than hydrocarbons. The $n$-alcohols were the only oxygencontaining compounds detected in the samples.

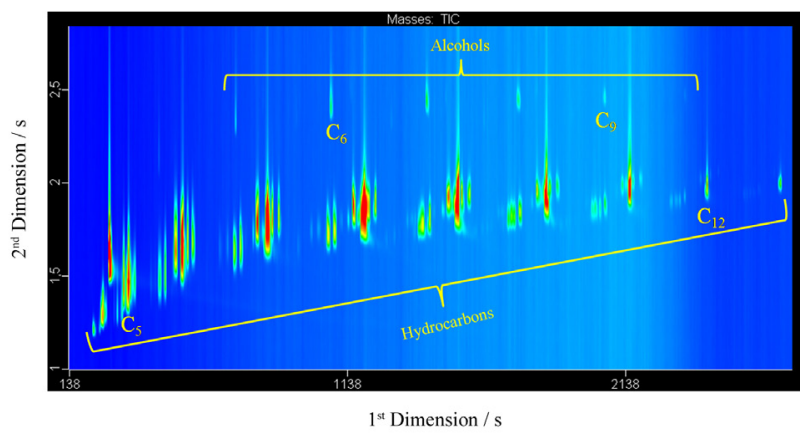

Figure 3. Two-dimensional chromatogram for FT1-L sample showing the complete separation of alcohols from hydrocarbons: $\mathrm{C}_{5}, n$-pentane; $\mathrm{C}_{6}, n$-hexanol; $\mathrm{C}_{9}, n$-nonanol; $\mathrm{C}_{12}, n$-dodecane.

The two-dimensional chromatograms were structured so that the compounds are resolved into groups. Each group 
is formed by the $n$-alkanes, branched alkanes and alkenes with the same number of carbon atoms and the $n$-alcohol with less two carbon atoms, Figure $4 \mathrm{a}-\mathrm{c}$. The advantages of $\mathrm{GC} \times \mathrm{GC}$ can be observed even if concerning only the ${ }^{1} \mathrm{D}$, as $\mathrm{GC} \times \mathrm{GC}$ provides thinner peak widths than conventional GC. In Figure $4 \mathrm{~b}$ it can be observed that the separation of four branched alkanes had good resolution in ${ }^{1} \mathrm{D}$.

In ${ }^{1} \mathrm{D}$ chromatography employing non-polar stationary phases with separation based on boiling point differences, the elution order is: the 1 -alkenes elutes before the $n$-alkanes followed by the cis-2-alkene and the trans-2-alkenes. ${ }^{30}$ As the number of carbon increases, the cis-2-alkenes peak elutes closer to the $n$-alkanes peak, and in some cases they can be covered by the $n$-alkanes peak. ${ }^{29}$ This can lead to inaccurate determinations for $n$-alkanes and alkenes. This problem was not observed in $\mathrm{GC} \times \mathrm{GC}$ using polar versus non-polar configuration because alkanes and alkenes form two chromatographic bands in this case..$^{29,30}$

Such problem was also not observed in this study either, Figure $4 \mathrm{c}$ shows the $\mathrm{C}_{21}$ group where the resolution between the $n$-alkane and cis-2-alkene peaks can be seen; this resolution was effective throughout the whole chromatogram. Although alkanes and alkenes have similar retention times in the non-polar ${ }^{1} \mathrm{D}$, the use of modulation provides higher resolution in GC $\times$ GC-TOFMS, even in ${ }^{1} \mathrm{D}$.

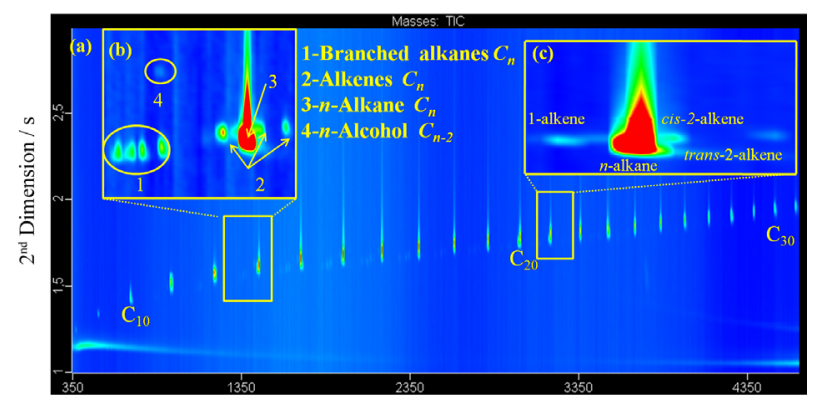

$1^{\text {st }}$ Dimension / s

Figure 4. (a) Overview of the two-dimensional chromatogram for FT1-S sample: $\mathrm{C}_{10}, n$-decane; $\mathrm{C}_{20}, n$-eicosane; $\mathrm{C}_{30}, n$-triacontane. (b) Expansion of $\mathrm{C}_{n}$ group showing the structuring of the compounds on the chromatographic plane, in this case $n=13$. (c) Expansion of the $C_{21}$ group showing the resolution between $c i s$-alkene isomer and $n$-alkane.

All samples presented $n$-alkanes as a major class, Figure 5, whereas for solid samples the $n$-alkanes content represents $80-90 \%$ of the phase, for liquid samples $n$-alkanes it is responsible for $50-60 \%$ of the phase.

Unlike the solid samples, the liquid samples showed levels of alkenes higher than branched alkanes. The oxygencontaining compounds represent a minor class in both liquid $(<2 \%)$ and solid samples $(<0.5 \%)$.

The $\mathrm{CO}_{2}$ effect on FT product composition was also evaluated. The samples obtained with $\mathrm{CO}_{2}$, FT2-L (55\%) and FT2-S $(87 \%)$ presented lower levels of $n$-alkanes than (a)

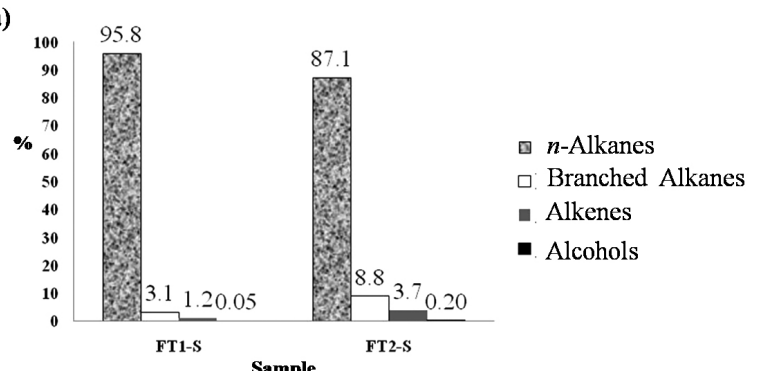

(b)

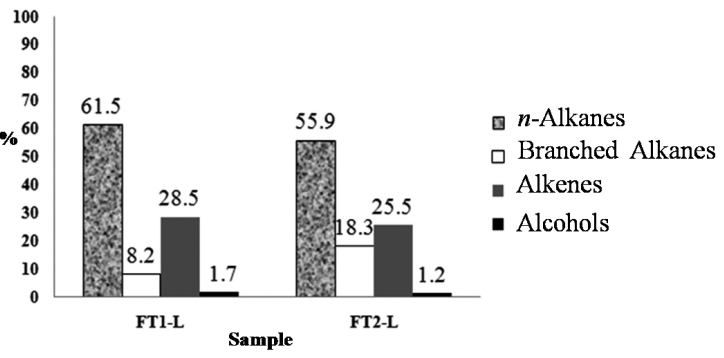

Figure 5. Comparison between the solid (a) and liquid (b) samples showing the relative proportion of $n$-alkanes, branched alkanes, alkenes and alcohols.

the FT1-L (61\%) and FT1-S (95\%) samples. The process of branching of carbon chains was favored by the $\mathrm{CO}_{2}$, because the levels of branched alkanes were higher in samples FT2-L and FT2-S than in the samples obtained without $\mathrm{CO}_{2}$.

For both cases (FT synthesis with and without $\mathrm{CO}_{2}$ ), the total amount of alkenes in the liquid phase, $28 \%$ (FT1-L) and 25\% (FT2-L), was higher than in the solid phase, $1 \%$ (FT1-S) and 3\% (FT2-S). Concerning the total amount of alcohols, were just observed few variations in both cases.

An observed effect of $\mathrm{CO}_{2}$ in the FT product selectivity, for all classes, was that $\mathrm{CO}_{2}$ favored the formation of compounds with lower molecular weights. In the sample FT2-L $n$-alkanes $\mathrm{C}_{5}-\mathrm{C}_{9}$ represented $70 \%$ of all $n$-alkanes detected, while this range represented $50 \%$ of $n$-alkanes detected in FT1-L, Figure 6a. In the sample FT2-S $n$-alkanes $\mathrm{C}_{9}-\mathrm{C}_{14}$ represented $44 \%$ of the overall composition of these compounds, while for FT1-S this range represented $27 \%$, Figure $6 \mathrm{~b}$.

The effect of favoring the formation of compounds with lower molecular weights was also observed for branched alkanes and alkenes, but was more evident in the distribution of $n$-alcohols. In the liquid samples, the $n$-alcohols detected ranged from $\mathrm{C}_{4}$ to $\mathrm{C}_{12}$, but $n$-pentanol and $n$-hexanol represented $60 \%$ of all $n$-alcohols detected in the sample FT2-L, while in the sample FT1-L these compounds represented $32 \%$ of alcohols detected. The range of $n$-alcohols detected for solid samples ranged from $\mathrm{C}_{10}$ to $\mathrm{C}_{19}$ and $n$-tridecanol was the major compound for FT1-S while for FT2-S the range was from $\mathrm{C}_{7}$ to $\mathrm{C}_{15}$ 

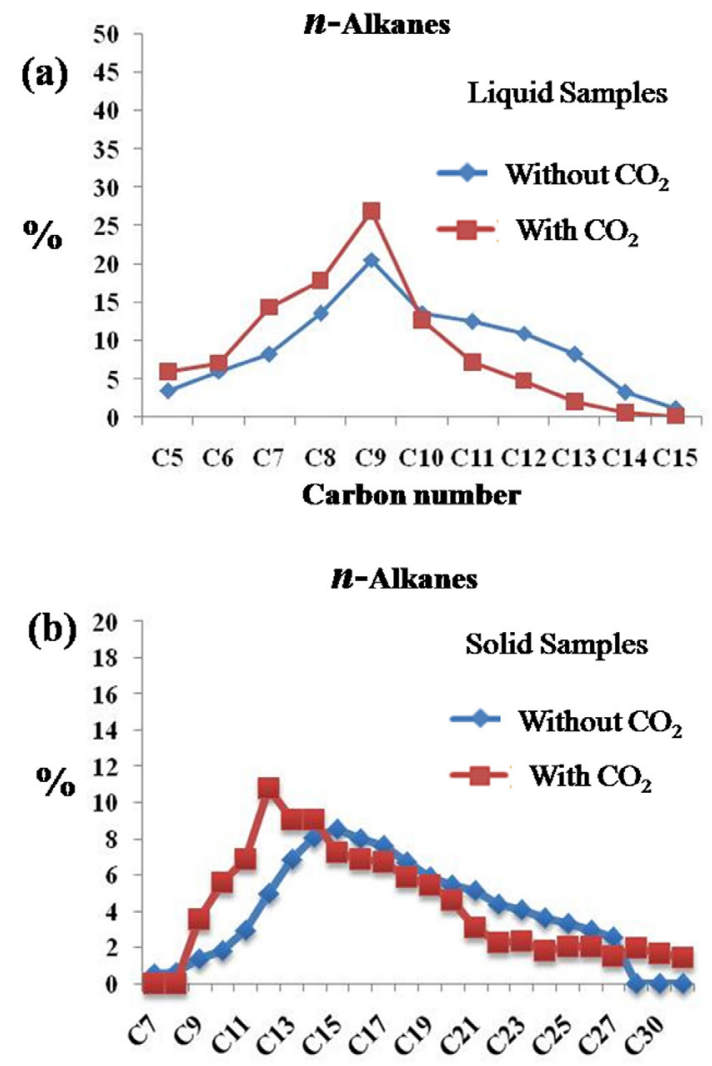

Carbon number
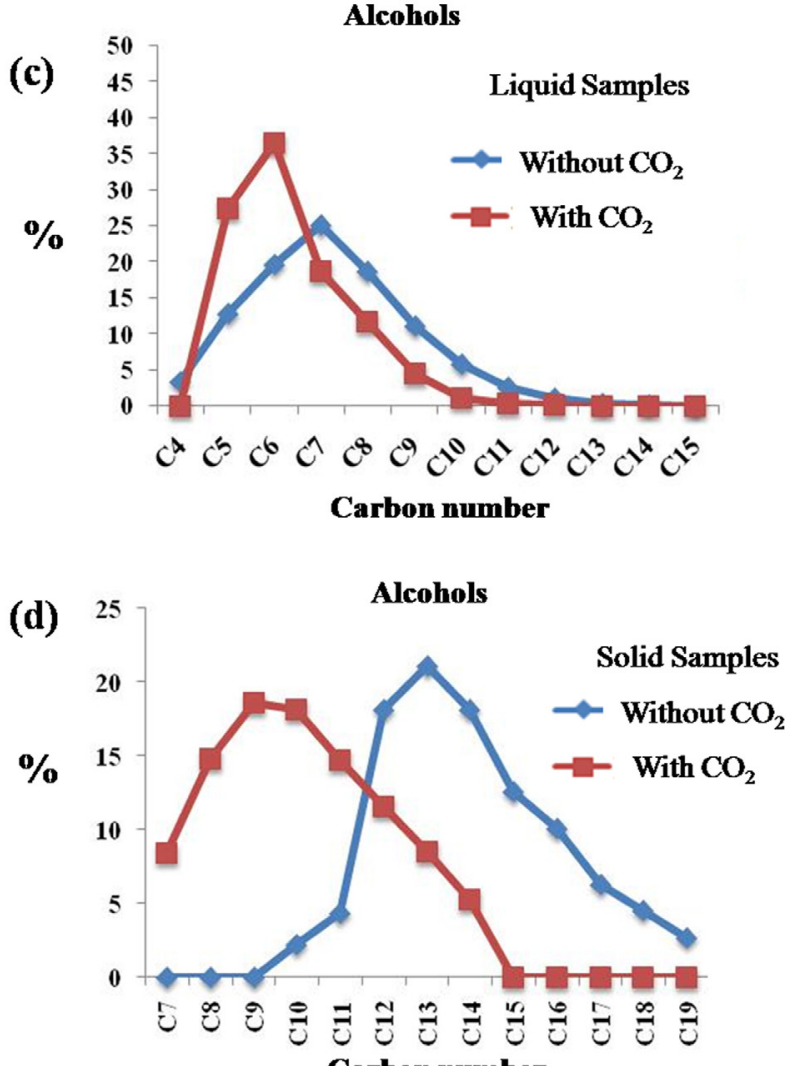

Carbon number

Figure 6. Comparison of the distribution of $n$-alkanes (a-b) and $n$-alcohols (c-d) detected in liquid and solid samples regarding carbon number. The effect of $\mathrm{CO}_{2}$ to promote the formation of compounds with lower molecular weights is shown on all graphs.

and $n$-nonanol was the major compound, which was not detected in FT1-L sample, Figure 6c-d.

\section{Conclusions}

GC $\times$ GC-TOFMS was able to resolve unresolved material as observed in the analysis of Fischer-Tropsch products by conventional GC. Higher levels of resolution for $n$-alkanes, branched alkanes, alkenes and $n$-alcohols analysis was provided by this technique.

The effect of $10 \%$ of $\mathrm{CO}_{2}$ on the FT product selectivity was pronounced. The main class of products ( $n$-alkanes, branched alkanes, alkenes and $n$-alcohols) shifted their carbon distribution to lower molecular weight compounds.

Although the products obtained in the presence of $\mathrm{CO}_{2}$ have a lower average molecular weight when compared with FT synthesis without $\mathrm{CO}_{2}$, the $n$-alkanes are the major compounds in both products and the total amount of olefins and alcohols did not change significantly. Then, small additions of $\mathrm{CO}_{2}$ on the Fischer-Tropsch process can be an environmentally attractive option, because it generates cleaner fuels with the $\mathrm{CO}_{2}$ reuse.

\section{Acknowledgments}

The authors thank CNPq (Brazilian Research Council) for fellowships. The study was supported by Cenpes/ Petrobras, FAPERJ and FUJB.

\section{References}

1. Steynberg, A. P.; Dry, M. E.; Fischer-Tropsch Technology, Elsevier: Amsterdam, 2004.

2. A Global Force. Tech Focus. Popular Mechanics, Sasol Ltd., 2007. http://www.sasol.com/sasol_internet/downloads/ SASOL_global_force_March07_1172224987155.pdf accessed in August 2011.

3. Ramos, A. L. D.; Marques, J. J.; Santos, V.; Freitas, L. S.; Santos, R. G. V. M.; Souza, M. M. V. M.; Quim. Nova, in press. http://quimicanova.sbq.org.br/qn/No\% 20Prelo/RV/RV10822. pdf accessed in August 2011.

4. Vannice, M. A; J. Catal. 1975, 37, 449.

5. Podgurski, H. H.; Kummer, J. T.; DeWitt, T. W.; Emmett, P. H.; J. Am. Chem. Soc. 1950, 72, 5382.

6. Storch, H.H.; Golumbic, N.; Anderson, R. B.; The Fischer-Tropsch and Related Synthesis, John Wiley \& Sons: New York, 1951. 
7. Ritschel, M.; Vielstich, W.; Chem. Ing. Tech. 1980, 52, 327.

8. Chuang, S. C.; Tian, Y.; Goodwin Jr., J. G.; Wender, I.; J. Catal. $\mathbf{1 9 8 5}, 96,396$.

9. James, O. O.; Mesubi, A. M.; Ako, T. C.; Maity, S.; Fuel Process. Technol. 2010, 91, 136.

10. Davis, B. H.; Catal. Today 2009, 141, 25.

11. Bao, B.; El-Halwagi, M. M.; Elbashir, N. O.; Fuel Process. Technol. 2010, 91, 703.

12. Kim, Y. H.; Jun, K. W.; Joo, H.; Han, C.; Song, I. K.; Chem. Eng. J. 2009, 155, 427.

13. Yagi, F.; Kanai, R.; Wakamatsu, S.; Kajiyama, R.; Suehiro, Y.; Catal. Today 2005, 104, 2.

14. Ha, K. S.; Bae, J. W.; Woo, K. J.; Jun, K. W.; Environ. Sci. Technol. 2010, 44, 1412.

15. Yao, Y.; Hildebrandt, D.; Glasser, D.; Liu, X.; Ind. Eng. Chem. Res. 2010, 49, 11061.

16. Dorner, R. W.; Hardy, D. R.; Williams, F. W.; Davis, B. H.; Willauer, H. D.; Energy Fuels 2009, 23, 4190.

17. Lui, Z.; Phillips, J. B.; J. Chromatogr. Sci. 1991, 29, 227.

18. von Mühlen, C.; Zini, C. A.; Caramão, E. B.; Marriott, P. J.; Quim. Nova 2006, 29, 765.

19. Pedroso, M. P.; de Godoy, L. A. F.; Fidélis, C. H. V.; Ferreira, E. C.; Poppi, R. J.; Augusto, F.; Quim. Nova 2009, 32, 421.

20. Welke, J. E.; Zini, C. A.; J. Braz. Chem. Soc. 2011, 22, 609.
21. von Mühlen, C.; Khummueng, W.; Zini, C. A.; Caramão, E. B.; Marriott, P. J.; J. Sep. Sci. 2006, 29, 1909.

22. Adahchour, M.; Beens, J.; Brinkman,U. A. T.; J. Chromatogr., A 2008, 1186, 67.

23. Ávila, B. M. F; Aguiar, A; Gomes, A. O.; Azevedo, D. A.; Org. Geochem. 2010, 41, 863.

24. Aguiar, A.; Silva Jr., A. I.; Azevedo, D. A.; Aquino Neto, F. R.; Fuel 2010, 89, 2760.

25. Silva, R. S. F.; Aguiar, H. G. M.; Rangel, M. D.; Azevedo, D. A.; Aquino Neto, F. R.; Fuel 2011, 90, 2694.

26. Tran, T. C.; Logan, G. A.; Grosjean, E.; Harynuk, J.; Ryan, D.; Marriott. P. J.; Org. Geochem. 2006, 37, 1190.

27. Tran, T. C.; Logan, G. A.; Grosjean, E.; Ryan, D.; Marriott, P. J.; Geochim. Cosmochim. Acta 2010, 74, 6468.

28. Vendeuvre, C.; Bertoncini, F.; Duval, L.; Duplan, J. L.; Thiébaut, D.; Hennion, M. C.; J. Chromatogr., A 2004, 1056, 155.

29. Grobler, T.; Claeys, M.; van Steen, E.; van Vuuren, M. J. J.; Catal. Commun. 2009, 10, 1674.

30. Westhuizen, R.; Crous, R.; Villiers, A.; Sandra, P.; J. Chromatogr., A 2011, 12178334.

Submitted: May 1, 2011

Published online: September 13, 2011 